\title{
Full-term newborns' readiness during the first breastfeeding in rooming-in
}

\author{
Prontidão do recém-nascido a termo durante a primeira mamada em alojamento conjunto
}

Fernanda Luciana Calegari ${ }^{1}$, Bianca Jora Barbieratto ${ }^{1}$, Cristina Ide Fujinaga ${ }^{2}$, Luciana Mara Monti Fonseca ${ }^{1}$, Caroline Ramos de Oliveira ${ }^{3}$, Adriana Moraes Leite ${ }^{1}$

Objective: to analyze the full-term newborn's readiness to suck the mother's breast in the first breastfeeding in rooming-in. Methods: analytical, quantitative study with 43 full-term newborns. Results: the states of sleep and wakefulness prevailing before breastfeeding were $41.9 \%$ alert and quiet during breastfeeding, $48.8 \%$ active sleep. In all domains assessed in the conduction of breastfeeding, the favorable signs had the highest percentage: Body posture (85.6\%); Newborn responses (82.3\%); Emotional bond (73.8\%); Breast anatomy (100.0\%); Suction by the newborn (86.1\%); Time spent in the suction (78.4\%). The average of the breastfeeding time was 12.08 minutes. Conclusion: full-term newborns showed good readiness to suck maternal breast in the first breastfeeding, since they prevailed in active state, showed good frequency of suction and in the conduction of breastfeeding, most of the signs were favorable to it.

Descriptors: Breast Feeding; Newborn; Rooming-in Care.

Objetivo: analisar a prontidão do recém-nascido a termo para sugar a mama materna na primeira mamada em alojamento conjunto. Métodos: estudo quantitativo, analítico, realizado com 43 recém-nascidos a termo. Resultados: os estados de sono e vigília predominantes antes da mamada foram: $41,9 \%$ alerta quieto e, durante mamada, 48,8\%, sono ativo. Em todos os domínios avaliados na condução da mamada, os sinais favoráveis apresentaram o maior percentual: Postura corporal (85,6\%); Respostas do recém-nascido (82,3\%); Vínculo emocional (73,8\%); Anatomia da mama (100,0\%); Sucção do recém-nascido (86,1\%); Tempo gasto na sucção $(78,4 \%)$. A média do tempo da mamada foi de 12,08 minutos. Conclusão: recém-nascidos a termo apresentaram boa prontidão para sugar a mama materna na primeira mamada, uma vez que prevaleceram em estado ativo, apresentaram boa frequência de sucção e, na condução da mamada, a maioria dos sinais apresentou-se favorável a ela.

Descritores: Aleitamento Materno; Recém-Nascido; Alojamento Conjunto.

\footnotetext{
${ }^{1}$ Escola de Enfermagem de Ribeirão Preto, Universidade de São Paulo. Ribeirão Preto, SP, Brazil.

${ }^{2}$ Universidade Estadual do Centro-Oeste. Irati, PR, Brazil.

${ }^{3}$ Centro de Referência Saúde da Mulher. Ribeirão Preto, SP, Brazil. 


\section{Introduction}

Breastfeeding was established and has been reaffirmed over the years as a strategy in primary care to reduce child morbidity and mortality, especially in developing countries. Its promotion is among the lines of care of the Datebook for Comprehensive Child Health and Reduction of Infant Mortality ${ }^{(1)}$.

In this sense, movements have been created to promote breastfeeding, such as the "BabyFriendly Hospital Initiative". It is noteworthy, in the perspective of birth humanization, the fourth and the seventh step of this initiative, which are critical for the establishment of the mother-baby bond, for the increased incidence of early hospital breastfeeding, and for the duration and success of breastfeeding ${ }^{(2-3)}$.

Despite the efforts in favor of birth humanization, a number of interventional procedures in labor and delivery are still present in practice, which can interfere with the process of birth and in maternal and neonatal conditions for the initiation of breastfeeding and, as a consequence, in the process of breastfeeding ${ }^{(4)}$.

One must consider, however, that the success of breastfeeding depends on numerous factors. With respect to neonatal factors: gestational age, weight, physiological and clinical stability, muscle tone, previous suction experience, facilitation of the baby's behavioral organization, state of consciousness, environmental control and posture ${ }^{(5)}$.

Regarding the birth process, the moment of environment transition from inside to outside the uterus is delicate and marked by several changes to the newborn. In the womb, the fetus has a cozy atmosphere with constant temperature and light, and the noises are heard smoothly. At birth, the neonate is faced with aversive, stressful and painful procedures, arising from technological advances of care. These procedures mostly produce physiological and behavioral disorganization in neonates, reflecting as negative to them ${ }^{(6)}$. Thus, after the birth, the newborn must adapt gradually to the extra-uterine environment, overcoming the difficulties necessary for their development ${ }^{(7)}$.

As to the state of sleep and wakefulness of the newborn in the first hours of life, they tend to be more sleepy depending on the dosage of drugs received by the mother in analgesia. High plasma levels of analgesics have side effects like depression of the nervous system and, consequently, the depressed state of the newborn, with negative repercussions in the first hours of life for breastfeeding ${ }^{(8)}$.

Initiating breastfeeding within the first hour of life is directly linked to the longer duration of breastfeeding in the child's life and, consequently, to reduce child mortality ${ }^{(9-10)}$.

Among the recommended actions to support breastfeeding, it is of fundamental importance observing each pair of mother/newborn during the breastfeeding. This activity has been proposed to identify mothers and babies who need additional support, and it has been proposed by the United Nations Children's Fund, an observation form to assess breastfeeding and to guide this activity, which contains the "signs that breastfeeding is going well" and "signs that breastfeeding is not going well" regarding this evaluation in different domains: body posture, newborn responses, emotional bond of the mother, breast anatomy, suction by the newborn and time spent in the suction ${ }^{(11)}$.

Whereas the quality of suction is essential in the early days of life for breastfeeding prognosis, since it can cause problems such as nipple injury and little intake of colostrum in situations when it is not effective, and that the newborn's readiness to suck maternal breast can be influenced by the labor and birth conditions, the objective of this study was to analyze the full-term newborn's readiness to suck maternal breast in the first breastfeeding in roomingin. 


\section{Methods}

This is an analytical study conducted in a ChildFriendly maternity of the State of Sao Paulo, Brazil. The sample consisted of newborns whose birth took place between May and November 2011, in a total of 43 newborns.

Inclusion criteria were: newborns delivered vaginally, admitted to rooming-in, born with gestational age between 37 and 41 weeks and six days, with Apgar $\geq 7$ in the 5th minute, the children of first-time mothers, with protruding nipples. Exclusion criteria were: congenital or acquired disease, affecting the nervous or stomatognathic system that interferes with mechanical suction, having seropositive mothers to the Acquired Immunodeficiency Virus, having diabetic mother or with nipple trauma.

The characterization variables of newborns obtained in medical records were sex, Apgar, weight, skin-to-skin contact immediately after birth, early breastfeeding and hours of life on the first feed in rooming-in.

As the adopted concept of readiness ${ }^{(7)}$, it was considered in the newborn's readiness to suck the mother's breast in the first feed: state of sleep and wakefulness, frequency of suction and conduction of breastfeeding.

The variables sleep and wakefulness, suction and conduction of the feed were filmed. The states of sleep and wakefulness were analyzed before and at the end of breastfeeding, highlighting the favorable or unfavorable signs. The states of sleep and wakefulness were classified ${ }^{(12)}$, filmed and subsequently marked in specific instrument before and during breastfeeding.

To calculate the newborns' average of sucks per minute, authors divided the total of suctions observed and recorded by the total time of feed in minutes.

The conduction of feed considered the "signs that breastfeeding is going well" (favorable) and "signs that breastfeeding is not going well" (unfavorable) contained in the Breastfeeding Observation Form with the following domains: body posture, newborn responses, emotional bond by the mother, breast anatomy, newborn suction and time spent on suction ${ }^{(11)}$.

The newborn's state of sleep and wakefulness was analyzed and recorded two minutes before and during breastfeeding. For this, the binomial was positioned, and the video recording started with the beginning of feeding until the end thereof. Subsequently, during the observation of the video record, the items analyzed were classified as "favorable" or "unfavorable" signs. The classification of items depended on the predominance of one of these signs throughout the feed.

To record, view and edit the video, and to make the subsequent coding of behavioral parameters of newborns and breastfeeding elements, two cameras were used. It was obtained the percentage of agreement between two researchers from a random sample of $33.0 \%$ of the video record and the concordance rates greater than or equal to $80.0 \%$ between the observers were established as appropriate, and the concordance index was $91.0 \%$.

With the aid of software R comparisons were performed using the Kruskal-Wallis Test, and when there was difference between any pair of groups, the Dunn's post-test was performed.

The study complied with the formal requirements contained in the national and international regulatory standards of research involving human beings.

\section{Results}

Of the 43 infants in the study, 26 (60.5\%) were female and 17 (39.5\%) were male. Regarding the first minute Apgar, 11 (25.5\%) 10 (23.3\%) 18 (41.9\%) and four (9.3\%) had Apgar 7, 8, 9 and 10; and in the fifth minute, two (4.7\%) 15 (34.8\%) and 26 (60.5\%) received Apgar 8, 9 and 10, respectively. The weight varied between 2245 and 4130 grams, with an average of 3190.1 grams.

Of the newborns, 36 (83.7\%) had clear Amniotic Fluid with lumps and seven (16.3\%), fluid meconium; 
$69.8 \%$ of neonates underwent aspiration of airway; 17 (39.5\%) were placed in skin-to-skin contact immediately at birth and only four (9.3\%) were breastfed early in the delivery room. The average life time when they started receiving breastfeeding was 1 hour $23 \mathrm{~min}$ and $31 \mathrm{~s}$ and a median of 76 minutes.

Before breastfeeding, two (4.7\%) newborns were in deep sleep, eight (18.6\%) in active sleep, 18 $(41.9 \%)$ in quiet alert state, $10(23.3 \%)$ in active alert and five $(11.5 \%)$ in crying state. It is noteworthy that none was in the sleepy state. During breastfeeding, the state of active sleep was prevalent in 21 (48.8\%) newborns, seven (16.3\%) remained in deep sleep, six $(13.9 \%)$ were sleepy, one $(2.4 \%)$ were in quiet alert, eight (18.6\%) were in active alert. Adding to the active and alert states (quiet alert + active alert + active sleep), 36 (83.8\%) newborns were found alert and active before starting the feed and 30 (69.7\%) newborns remained in these states during breastfeeding. Table 1 shows this data.

Table 1 - Distribution of states of sleep and wakefulness before and during the first breastfeeding in rooming-in according to their frequencies and confidence intervals

\begin{tabular}{lcccc}
\hline \multirow{2}{*}{ Sleep state (n=43) } & \multicolumn{2}{c}{ Before } & \multicolumn{2}{c}{ During } \\
\cline { 2 - 5 } & $\mathbf{n ( \% )}$ & $\mathbf{C I}(\mathbf{9 5 \%})^{*}$ & $\mathbf{n ( \% )}$ & $\mathbf{C I}(\mathbf{9 5 \% )}$ \\
\hline Deep & $2(4.7)$ & $0.6-15.8$ & $7(16.3)$ & $6.8-30.7$ \\
Active & $8(18.6)$ & $8.4-33.4$ & $21(48.8)$ & $33.3-64.5$ \\
Sleepy & - & - & $6(14.0)$ & $5.3-27.9$ \\
Quiet alert & $18(41.9)$ & $27.0-57.9$ & $1(2.3)$ & $0.1-12.3$ \\
Active alert & $10(23.3)$ & $11.8-38.6$ & $8(18.6)$ & $8.4-33.4$ \\
Crying & $5(11.5)$ & $3.9-25.1$ & - & - \\
*Confidence Interval & & & &
\end{tabular}

With regard to the total time spent during the first feeding of the newborn in rooming-in, the average reported was 12.08 minutes, with a median of 11 minutes and standard deviation of +7.34.

The performance of newborns during breastfeeding ranged from zero to 1,053 suctions, averaging 353.58 , and the average of suctions per minute was
26.13 , ranging from zero to 56.6 suctions per minute, as shown in Table 2.

Table 2 - Mean ( \pm standard deviation), median and maximum values of suctions per breastfeeding and per minute during the first feeding of newborns in rooming-in

\begin{tabular}{lcc}
\hline Measures & $\begin{array}{c}\text { Number of suctions } \\
\text { per breastfeeding }\end{array}$ & $\begin{array}{c}\text { Number of suctions } \\
\text { per minute }\end{array}$ \\
\hline Mean & 353.58 & 26.13 \\
Median & 323.50 & 27.40 \\
Standard deviation & \pm 281.89 & \pm 16.58 \\
Maximum & 1053 & 56.6 \\
\hline
\end{tabular}

As for the favorable and unfavorable signals to breastfeeding, the favorable signs to breastfeeding were: body posture (85.6\%), newborn responses (82.3\%), emotional bond (73.8\%), maternal breast anatomy (100.0\%), suction by the newborn (86.1\%) and time spent in the suction (78.4\%). These results are shown in Table 3.

Table 3 - Characterization of the first breastfeeding in rooming-in according to the favorable and unfavorable signals to feed, their frequencies and confidence intervals

\begin{tabular}{lcccc}
\hline & $\begin{array}{c}\text { Favorable } \\
\text { signs }\end{array}$ & CI(95\%)* & $\begin{array}{c}\text { Unfavorab- } \\
\text { le signs }\end{array}$ & CI(95\%)* \\
\cline { 2 - 5 } & $\mathbf{n}(\%)$ & & $\mathbf{n}(\%)$ \\
\hline Body posture & $214(85.6)$ & $80.6-89.7$ & $36(14.4)$ & $10.3-19.4$ \\
Newborn response & $177(82.3)$ & 76.6 & $38(17.7)$ & 12.8 \\
$\begin{array}{l}\text { Emotional bond mother } \\
\text { and baby }\end{array}$ & & & \\
Maternal breast anatomy & $172(13.8)$ & $65.2-81.2$ & $33(26.2)$ & $18.8-34.8$ \\
Suction by the newborn & $223(86.1)$ & $81.3-90.1$ & $36(13.9)$ & $9.9-18.7$ \\
Time spent in the suction & $29(78.4)$ & $51.8-90.2$ & $8(21.6)$ & $9.8-38.2$ \\
\hline *Confidence Interval & & & & - \\
\hline
\end{tabular}

After grouping the states quiet alert and active alert, it was noted that such states remain at all times predominating with a high percentage of favorable signals to breastfeeding. In grouping the states deep sleep and active sleep, there is variation in this percentage, and in the sleepy state there is also variation 
in the percentage of favorable signs, but with lower prevalence of newborns. Thus, breastfeeding tends to have more favorable signals when the newborn is in alert state. It was also noted that as the breastfeeding takes place, newborns start to present themselves in a more sleep state. After 20 minutes of sucking maternal breast, newborns are no longer on alert status.

\section{Discussion}

A previous study, in which breastfeeding was observed through the same observation form used in this study, demonstrated the occurrence of favorable scores (good) in the aspects of the baby's position and suction. Less favorable scores (regular and bad), which showed higher number of behaviors suggestive of difficulty, occurred in the general observation of the mother and how they hold the baby ${ }^{(13)}$.

The full-term newborn and healthy infants without clinical complications have all the necessary conditions for the start of feeding in the maternal breast. The first function to become effective in the stomatognathic system is swallowing, defined as reflexively action that is critical to survival and that happens when a quantity of milk is stored inside the baby's mouth, important for oral feeding and the proper development of sensory oral motor system. To this end, there must be coordination of oral reflexes, as well as lip seal, appropriate tongue movement, its protrusion for obtaining milk. It is important to the success of breastfeeding, and the tongue distension ability is fundamental during the extraction of milk from the nipple ducts and jaw, suction rhythm, with alternating breaks and coordination between suction movements, swallowing and breathing ${ }^{(5)}$.

Data from this study corroborate those of another, whose newborns were full-term and healthy, without clinical complications, in theory, with all the necessary conditions for the start of breastfeeding ${ }^{(14)}$.

The total time spent during the first feeding of the newborn in rooming-in was on average 12.08 minutes. The optimal breastfeeding, however, is not linked exclusively to the duration of breastfeeding. The newborn, with few suctions, may obtain a quantity of milk that meets their needs, that is, an amount of nutrients needed to their survival. Letting them suckle spontaneously, not stipulating hours or length of time, is one of the ways to make breastfeeding more efficient, after all, every newborn has their own nutritional demand. This explains why the newborn, when satisfied by milk intake, loosen the breast spontaneously ${ }^{(14)}$.

In another previous study, the median of suctions per minute was $36^{(15)}$, but the time interval between the birth of the babies and the data collection was about four days after delivery, unlike the present study. Another study reported the frequency of suction to breastfeeding before starting the procedure of administering the vaccine against hepatitis B, i.e., with newborns averaging 6.93 hours of life, and the number of suctions was 10 to 28 suctions per minute ${ }^{(15)}$.

This fact confirms that when mother and baby stay together after birth, there is a series of sensory, hormonal, physiological, immunological and behavioral events, which aid in the bond between mother and the baby, which contributes to the union of both and assists in the development of relationship ${ }^{(16)}$.

As the breastfeeding started, on average, at 1 hour and 23 minutes of life of the newborn, the data corroborate the literature, since before and during breastfeeding most infants were in readiness ${ }^{(17)}$.

The fact that mothers had received guidance before and during breastfeeding may have influenced the results that were more favorable than unfavorable to the breastfeeding, but for ethical reasons, such intervention was necessary.

Most newborns had early skin contact and were breastfed in the first hour after birth, which affected the quality of the first feed in rooming-in. Moreover, the readiness inherent in their physiology to suck the mother's breast in the first hours of life determined the pattern of feeding thereof, in which the facilities have overcome the difficulties.

Early rooming-in, i.e., the referral of mother 
with her newborn soon after birth to the infirmary showed a favorable practice for obtaining favorable signs in the first feed.

A limitation of the study was in the fact that the full-term newborn's readiness to suck maternal breast was analyzed only in the first feed in rooming-in. It is recommended, therefore, that further studies evaluate more feedings, thus enabling an analysis of average time spent during feedings of full-term newborns in rooming-in and ultimately assessing the stages of hours of life and quality of feed in this situation.

This study has advanced from previous studies with regard to the analysis of the first feed, specifically in rooming-in, and in the relationship between the state of sleep and wakefulness and quality of suction by newborns.

\section{Conclusion}

Newborns presented standard of normality for this situation, that is, full-term and low risk newborns are ready to suck in the first few hours of life, with good suction of maternal breast, being in active state with good frequency of suction and with most of the domains analyzed in the conduction of feeding favorable to breastfeeding.

Early encouragement to breastfeeding at birth has proven effective and imperative for successful breastfeeding, as newborns were put to breastfeed in the first hour of life and thus were ready to breastfeed at this time, with good performance during breastfeeding.

\section{Collborations}

Calegari FL, Barbieratto BJ and Leite AM contributed to the study design, literature review, analysis and writing of the article. Fijinaga CI, Fonseca LMM and Oliveira CR contributed to the literature review, analysis and writing of the article. All authors contributed to the critical review and approval of the version to be published.

\section{References}

1. Ministério da Saúde (BR). Gestões e gestores de políticas públicas de atenção à saúde da criança: 70 anos de história. Brasília: Ministério da Saúde; 2011.

2. Crenshaw JT. Health birth practice: keep mother and baby together- it's Best for mother, baby and breastfeeding. J Perinatal Educ. 2014; 23(4):2117.

3. Monte GCSB, Leal LP, Pontes CM. Avaliação do $4^{\circ}$ passo para promoção do aleitamento materno em hospital amigo da criança. Rev Rene. 2012; 13(4):861-70.

4. Oliveira PMP, Pagliuca LMF. Assessment of an educational technology in the string literature about breastfeeding. Rev Esc Enferm USP. 2013; 47(1):205-12.

5. Geddes DT, Chawick LM, Kent JC, Garbi NCP, Hartamann PE. Ultrasound imaging of infant swallowing during breast-feeding. Dysphagia. 2010; 25(3):183-9.

6. Vivancos RBZ, Leite AM, Scochi CGS, Santos CB. The skin to skin contact at birth and newborn crying during vaccination against Hepatitis B. Acta Paul Enferm. 2010; 23(4):461-5.

7. Tornese G, Ronfani L, Pavan C, Demarini S, Monasta L, Davanzo R. Does the LATCH score assessed in the first 24 hours after delivery predict nonexclusive breastfeeding at hospital discharge? Breastfeeding Med. 2012; 7(6):423-30.

8. Radzyminski S. The effect of ultra low dose epidural analgesia on newborn breastfeeding behaviors. J Obstet Gynecol Neonatal Nurs. 2013; 32(3):322-31.

9. Prade LS, Bolzan GP, Weinmann ARM. Influência do estado comportamental nos padrões de sucção de recém-nascidos pré-termo. Audiol Commun Res. 2014; 19(3):230-5.

10. Esteves TMB, Daumas RP, Oliveira MIC, Andrade CAF, Leite IC. Fatores associados à amamentação na primeira hora de vida: revisão sistemática. Rev Saúde Pública. 2014; 48(4):697-703.

11. World Health Organization. Positioning a baby at the breast. Genebra: WHO; 2008. 
12. Castral TC, Warnock F, Ribeiro LM, Vasconcelos MGL, Leite AM, Scochi CGS. Maternal factors regulating preterm infants' responses to pain and stress while in maternal kangaroo care. Rev Latino-Am Enfermagem. 2012; 20(3):435-43.

13. Vieira AC, Costa AR, Gomes PG. Boas práticas em aleitamento materno: Aplicação do formulário de observação e avaliação da mamada. Rev Soc Bras Enferm Ped. 2015; 15(1):13-20.

14. Hannula LS, Kaunonen ME, Puukka PJ. A study to promote breast feeding in the Helsinki Metropolitan area in Finland. Midwifery. 2014; 30(6):696-704.
15. Leite AM, Silva ACTO, Castral TC, Nascimento LC, Sousa MI, Scochi CGS. Breastfeeding and skin-to-skin contact for pain relief of newborns during hepatitis B vaccination. Rev Eletr Enferm [Internet]. 2015 [cited 2015 Feb. 22]; 17(3):1-8. Available from: https://www.fen.ufg.br/revista/ v17/n3/pdf/v17n3a01-en.pdf

16. Ho YJ, McGranth JM. Predicting breastfeeding duration related to maternal attitudes in a Taiwanese sample. J Perinalt Educ. 2011; 20(4):188-99.

17. Hockenberry MJ. Wong fundamentos de enfermagem pediátrica. Rio de Janeiro: Elsevier; 2011. 